\title{
The Chars Livelihoods Programme in Bangladesh: Factors that Enable, Constrain and Sustain Graduation
}

\author{
Matthew Pritchard, Stuart Kenward and Maksudul Hannan
}

\begin{abstract}
The Chars Livelihoods Programme (CLP) in Bangladesh aims to lift households out of extreme poverty by providing a comprehensive package of support. As with other poverty reduction programmes in Bangladesh, CLP's success is partly judged using the concept of graduation. Defining graduation and how to actually measure it has generated significant debate. This article, prepared by members of the team responsible for implementing the programme, explains how CLP's thinking in terms of defining and measuring graduation has evolved over time. The programme finally arrived at an agreed set of graduation criteria and a measurement methodology in early 2014. This article presents graduation rates. It goes on to outline the factors that constrain and enable graduation and offers a set of conclusions and lessons learned, including the need to ensure alignment between programme design, operations and graduation criteria; and ensuring that sustainability of impacts/graduation is monitored and evaluated.
\end{abstract}

\section{Background}

Bangladesh is a low-income country in Southeast Asia with a population of $156 \mathrm{~m}$. Despite significant declines in rural poverty, from 44 per cent in 2005, 35 per cent of the rural population still live below the national or 'upper' poverty line and 21 per cent live below the 'lower' poverty line (Government of Bangladesh 2010).

To combat poverty, Bangladesh's government, civil society and the international community have funded a variety of extreme poverty reduction programmes and BRAC's Challenging the Frontiers of Poverty Reduction Targeting the Ultra Poor (CFPR-TUP) is one of the most longstanding and well known. It is supported by UKaid through the Department for International Development (DFID), which also funds other extreme poverty-focused programmes such as Eradicating Extreme Poverty/Stimulating Household Improvements Resulting in Economic Empowerment (EEP/Shiree) (see Risner and Gadhavi, this IDS Bulletin) and the Chars Livelihoods Programme Phase 2 (CLP-2). These programmes all focus on extreme poverty or the ultra-poor; they all include elements such as asset transfers and capacity building; and they all judge their success or progress using the concept of 'graduation'.

Graduation itself is a term that has generated multiple definitions (and arguments over definitions). The three programmes noted above all use a similar graduation approach, but with differing indicators and thresholds (Table 1). Participants are considered to 'graduate' once they meet a certain pre-set number of indicators such as food security, asset base and income levels. Once a household has 'graduated', it is assumed to have moved out of extreme poverty.

\section{The Chars Livelihoods Programme}

'Chars' is a Bangla word that means riverine islands, or any low-lying flood-prone area. The regular flooding of the Jamuna, Padma and Teesta rivers deposits areas of sand, mud and silt that either become stand-alone islands, or become land as the rivers recede after the rainy season. Sixty years ago, the northwest chars had not been regularly settled; they were mainly used for seasonal cattle-grazing. However, the rising population and resulting land pressure in Bangladesh saw increasing numbers of people move permanently to these chars, even though 


\begin{tabular}{|c|c|c|c|}
\hline $\begin{array}{l}\text { Domain (based } \\
\text { mainly on CLP's } \\
\text { definitions) }\end{array}$ & CLP & Shiree & BRAC CFPR-TUP \\
\hline \multirow[t]{6}{*}{$\begin{array}{l}\text { Food security, } \\
\text { nutrition, } \\
\text { consumption }\end{array}$} & \multirow[t]{2}{*}{$\begin{array}{l}\text { HH eats } 3 \text { meals in a } \\
\text { day and consumes } 5 \\
\text { or more food groups in } \\
\text { the last week }\end{array}$} & $\begin{array}{l}\text { Required criteria: Fewer than } \\
2 \text { food-coping strategies used } \\
\text { in the last monitoring period } \\
\text { (e.g. eating lower quantity or } \\
\text { quality of food) }\end{array}$ & \multirow[t]{2}{*}{$\begin{array}{l}\text { Never faces chronic food } \\
\text { deficit }\end{array}$} \\
\hline & & $\begin{array}{l}\text { HH consumes } 6 \text { or more } \\
\text { types of food (food diversity) }\end{array}$ & \\
\hline & $\begin{array}{l}\mathrm{HH} \text { has access to } \\
\text { improved water supply } \\
\text { meeting CLP criteria }\end{array}$ & $\begin{array}{l}\text { Access to safe drinking water } \\
\text { (rural participants only) }\end{array}$ & Drinks tube-well water \\
\hline & $\begin{array}{l}\mathrm{HH} \text { has access to hygienic } \\
\text { latrine meeting CLP criteria }\end{array}$ & $\begin{array}{l}\text { Access to hygienic sanitation } \\
\text { (rural participants only) }\end{array}$ & Has sanitary latrine \\
\hline & $\begin{array}{l}\text { Presence of ash/soap near } \\
\text { to water point or latrine }\end{array}$ & - & - \\
\hline & - & $\begin{array}{l}\text { BMI of adult/HH head of } 18.5 \\
\text { or above; and not anaemic }\end{array}$ & - \\
\hline \multirow[t]{2}{*}{$\begin{array}{l}\text { Income, } \\
\text { expenditure }\end{array}$} & $\begin{array}{l}\mathrm{HH} \text { has had more than } \\
\text { one source of income } \\
\text { during the last } 30 \text { days }\end{array}$ & 2 or more jobs in $\mathrm{HH}$ & Has 3 or more income sources \\
\hline & - & $\begin{array}{l}\text { Income above HIES poverty } \\
\text { line }\end{array}$ & $\begin{array}{l}\text { Per capita income of } 50 \text { c per } \\
\text { day or more }\end{array}$ \\
\hline \multirow[t]{3}{*}{ Asset base } & $\begin{array}{l}\text { Productive assets worth } \\
\text { BDT30,000 or more }\end{array}$ & $\begin{array}{l}\text { Productive assets worth } \\
\text { BDT10,000 or more }\end{array}$ & - \\
\hline & - & $\begin{array}{l}4 \text { or more productive assets } \\
\text { in } \mathrm{HH}\end{array}$ & $\begin{array}{l}\text { Households own } \\
\text { livestock/poultry }\end{array}$ \\
\hline & - & $\begin{array}{l}\text { Access to cultivable land (rural } \\
\text { participants only) }\end{array}$ & - \\
\hline $\begin{array}{l}\text { Status of } \\
\text { females }\end{array}$ & $\begin{array}{l}\text { Female participant is able } \\
\text { to influence } \mathrm{HH} \text { decisions } \\
\text { regarding sale/purchase of } \\
\text { large investments, } \\
\text { e.g. cattle }\end{array}$ & $\begin{array}{l}\text { Positive gender } \\
\text { empowerment of female } \\
\text { adult member of } \mathrm{HH}\end{array}$ & \\
\hline \multirow[t]{2}{*}{ Vulnerability } & $\begin{array}{l}\text { HH has cash savings of } \\
\text { BDT3,000 or more }\end{array}$ & $\begin{array}{l}\text { Cash savings of BDT1,000 or } \\
\text { more }\end{array}$ & Has cash savings \\
\hline & $\begin{array}{l}\text { Homestead is above } \\
\text { highest-known flood level } \\
\text { in the area }\end{array}$ & - & House with roof made of tin \\
\hline $\begin{array}{l}\text { Access to } \\
\text { services }\end{array}$ & $\begin{array}{l}\text { HH has membership of a } \\
\text { social group }\end{array}$ & - & $\begin{array}{l}\text { School-aged children go to } \\
\text { school }\end{array}$ \\
\hline Health & - & No fever or diarrhoea & - \\
\hline
\end{tabular}




\begin{tabular}{l|l|l|l}
\hline $\begin{array}{l}\text { Domain (based } \\
\text { mainly on CLP's } \\
\text { definitions) }\end{array}$ & CLP & Shiree & BRAC CFPR-TUP \\
\hline $\begin{array}{l}\text { Other } \\
\text { Graduation } \\
\text { threshold }\end{array}$ & HH must achieve 6 of 10 & $\begin{array}{l}\text { All HHs must achieve the } \\
\text { 'required' indicator; } \\
\text { Rural HHs: } 6 \text { of } 12 \\
\text { supplementary indicators } \\
\text { (i.e. } 7 \text { of 13); } \\
\text { Urban HHs: } 4 \text { of } 12 \\
\text { supplementary indicators } \\
\text { (5 of 10; } 3 \text { indicators } \\
\text { do not apply) }\end{array}$ & HH must achieve 6 \\
\hline
\end{tabular}

Source Gadhavi and Pettersson (2013); Kenward and Hannan (2014); Hashemi and Umaira (2011).

they were at regular risk of being eroded by the rivers that created them. The population on the chars is recognised as being among the poorest and most vulnerable in Bangladesh.

The first phase of the Chars Livelihoods Programme (CLP-1) began in 2004 after an extensive design period:

There was to be investment in infrastructure and market development which would accelerate economic growth in the region supplemented by livelihood promotion interventions at community and household level. There was to be a major investment in 'voice' programming which was to lead to improvements in governance generally and to improved delivery of health and education services in particular (Hodson 2010).

The goal, purpose and outputs of CLP-1 were as follows:

- Goal: Halve extreme poverty in the riverine areas of Bangladesh by 2015;

- Purpose: Improve livelihood security for poor and vulnerable women, men and children living within the riverine areas of five districts of the northern Jamuna;

- Output 1: Reduced vulnerability of char dwellers through targeted provision of infrastructure and services;

- Output 2: Poor women and men char dwellers effectively sustain their livelihoods and engage in the local and national economy; and
- Output 3: Poor char dwellers are able to effectively influence local and national policy and service provision as citizens.

However, questions over the design and likelihood of success quickly rose and, during 2005, DFID and CLP-1 accepted that the original design was unlikely to be successful. Over the next year, the programme was redesigned with the same goal, but revised purpose and outputs, as follows.

- Purpose: Improved livelihood security for poor and vulnerable women, men and children living within the riverine areas of five districts of the northern Jamuna;

Output 1: Reducing environmental vulnerability;

- Output 2: Enhancing economic opportunities;

- Output 3: Improving social wellbeing and governance;

- Output 4: Increasing wellbeing through services;

- Output 5: Fostering learning and sharing (policies and institutions).

The redesign introduced many of the strategies that continue under CLP-2 today: infrastructure to reduce vulnerability and provide water and sanitation; a livelihoods approach based around asset transfer, stipends and supporting capacity building; social development activities; access to a safe place to save and borrow; and marketsbased activities, among others. This integrated package was based on BRAC's CFPR-TUP programme (Hodson 2010), but adapted to the specific circumstances of the chars, particularly 
the vulnerability profile of char dwellers and their exposure to regular flood risk.

\section{CLP-1 worked with 55,000 extreme poor} households in four phases, called cohorts, from 2006 to 2010 . Given the community focus of some of the assistance, it was estimated that up to 900,000 individuals benefited from some aspect of CLP-1 (Maxwell Stamp Plc 2010). It focused on chars in five districts: Kurigram, Gaibandha, Jamalpur, Bogra and Sirajganj.

The Chars Livelihoods Programme Phase 2 began in April 2010 and will continue until April 2016. It aims to lift approximately 78,000 households out of extreme poverty, or 23 per cent of the households (HHs) estimated to live permanently on the chars (Kenward and Islam 2010).

Phase 2 has an expanded geographical remit to include the districts of Rangpur, Lalmonhirat, Nilphamari, Pabna and Tangail. Approximately 34 per cent of households in CLP-2 operational districts are estimated to meet CLP's selection criteria (i.e. they are extremely poor).

CLP's support focuses on adult females, even where the head of household is male, for the following reasons:

- many husbands or adult males migrate to find work for long periods of the year, sometimes returning to the marital home for only a few weeks per year;

- men are often not available to look after assets, attend training sessions and so on;

- females are therefore often de facto heads of household;

- giving assets and training to women is intended to foster women's empowerment to counter some perceived negative aspects of traditional male-dominated culture in the chars, such as gender-based violence, discrimination against women, dowry and lack of 'voice' for females.

The 'core package of assistance' offered by CLP-2 to its core participant households (CPHHs) is provided for an average of 20 months. Although recognised as a somewhat arbitrary period, it was considered the best compromise between considerations around quality of assistance, likelihood of sustainability, management arrangements to reach the required scale of implementation, and cost.
The core package is made up of the following components:

- The Asset Transfer Project: transfers an incomegenerating asset worth up to BDT17,500 (approximately $£ 142$ ) to female participants. The CLP does not prescribe what the household should purchase, only requiring that it must be able to generate an income. The vast majority of participants (98 per cent) select cattle.

- Raising plinths (mounds of earth) for flood protection. The plinths, which are usually constructed by members of the local community under CLP's Infrastructure Employment Project (IEP), extend at least $60 \mathrm{~cm}$ above the highest-known flood level in the area.

- Subsidies to participant households to install improved water sources, and subsidies to all village households to construct sanitary latrines, whether or not they are receiving the core package of assistance.

- Fortnightly health clinics and training of village health workers. In addition to providing primary health care and family planning services, CLP provides deworming tablets, iron/folic acid tablets for pregnant or lactating women, and micronutrient supplements to children.

- Given that most participants choose cattle as their asset, the livestock market and value chain is a critical component of a livelihood. The CLP implements a market development project so that the livestock market works better for people on the chars.

- The CLP aims to raise the social awareness of char people on a number of issues, particularly: the status and empowerment of women; reducing the incidences of dowry and early marriage; promoting good hygiene practices; and educating char people on how to access government services. CLP participants attend weekly social development group meetings throughout the 18-month programme.

- CLP also aims to bring additional resources and organisations onto the chars to provide goods and services to char dwellers through its Partnerships programme. For example, BRAC now provides health services in some phasedout CLP areas.

\section{The evolution of graduation in CLP 3.1 CLP Phase 1}

The first phase of CLP began discussing graduation during 2008 as a means of assessing whether or not the programme was achieving its 


\section{Domain Indicators and explanation of thresholds}

Income/expenditure/ 1 Household has had more than one source of income during the last 30 days consumption

This threshold was chosen because diversification of livelihoods was considered a good strategy to generate sustainability in the risk-prone circumstance of the chars. See Barrett et al. (2013).

\section{Household achieves 'acceptable' food consumption score}

The 'acceptable food consumption score' method was developed by the WFP and requires a respondent to achieve at least 42 points out of 112, based on dietary diversity and nutrition density of the food eaten in the past week. This indicator was modified in 2014; see below.

\section{Nutrition 3 Household has access to improved water}

The water point had to meet CLP standards, mainly that it should have a concrete platform to prevent water seeping back down and contaminating the groundwater.

4 Household has access to a sanitary latrine (meeting all sub-criteria)

This required the latrine to have an unbroken water seal as well as be located at least $10 \mathrm{~m}$ from water points and food preparation areas.

\section{Presence of ash/soap near to water point or latrine}

\begin{tabular}{ll}
\hline Asset base & $\begin{array}{l}6 \text { Household owns productive assets worth more than BDT30,000 } \\
\text { This was chosen because it represented a doubling of the initial asset value of BDT15,000 } \\
\text { and was similar to the level chosen for CLP-1. }\end{array}$ \\
\hline Status of females & $\begin{array}{l}7 \text { Participant is able to influence household decisions regarding sale/purchase of large } \\
\text { investments, e.g. cattle } \\
\text { Assessed by self-report during annual surveys. }\end{array}$ \\
\hline Vulnerability & $\begin{array}{l}\text { 8 Homestead is above known flood level } \\
\text { 9 Household has cash savings more than BDT3,000 } \\
\text { This threshold was chosen because CLP had estimated that, for its emergency assistance } \\
\text { grants, around BDT3,000 would allow a HH to move and re-establish a homestead in the } \\
\text { event of a disaster. }\end{array}$ \\
\hline
\end{tabular}

Access to services $\quad 10$ Household has membership of social group

Such as a village savings and loans group, village development committee, other microfinance group, etc.

Source Kenward, Blackie and Islam (2012).

objectives. CLP-1's criteria were multidimensional, given that the management team took the view that income/expenditure indicators alone are too simplistic to reflect the multidimensional nature of poverty. However, there was no direct attempt to consolidate the statistics into a 'graduation figure' or report on the number of households that achieved them. The graduation criteria were thus used to assess whether the programme was graduating, rather than households.

\subsection{CLP Phase 2}

During Phase 2, thinking on graduation continued to evolve, driven in part by donor need to report on numbers of people being assisted and moving out of extreme poverty; and partly by CLP's assessment that previous graduation methods were not adequately illustrating participants' graduation or journey out of poverty.

After substantial debate, the CLP-2 Annual Review of 2011 recommended that graduation criteria should address reduced social as well as economic vulnerability.

An initial two-stage process was rejected by the Annual Review of 2012 as being too complex. It suggested a single set of ten equally-weighted indicators based on six themes which reflect all major aspects of the programme. Table 2 shows 


\begin{tabular}{|c|c|c|c|c|c|}
\hline & Cohort 2.1 & Cohort 2.2 & Cohort 2.3 & Cohort 2.4 & $\begin{array}{l}\text { Mean } \\
\text { graduation rate } \\
\text { Cohorts } 1-4\end{array}$ \\
\hline Total graduation ( 6 of 10 ) & $66.7 \%$ & $81.3 \%$ & $86.7 \%$ & $91.1 \%$ & $84.9 \%$ \\
\hline
\end{tabular}

the set of graduation criteria produced in October 2012.

A household was considered to have 'graduated' if they met at least six of these ten criteria. While this is, to a certain extent, an arbitrary line (why not five or seven?), nevertheless it largely fits with community perceptions and also with other practitioners' practices. The criteria are in line with many of the criteria used by communities on the chars to define their own wellbeing, as illustrated by research conducted by the CLP during 2011 (Kenward et al. 2011).

\subsection{Current CLP-2 position on graduation}

CLP-2 believes that graduation is a useful tool at the management level. It allows an overview of the extent to which a basket of important indicators has been achieved by its participants

Table 4 Sensitivity analysis, CLP-2 graduation rates

\begin{tabular}{ll}
\hline CLP-2 cohort description & $\begin{array}{l}\text { Average CLP-2 } \\
\text { cohorts }\end{array}$
\end{tabular}

Total \% graduating (i.e. meet

at least 6 out of 10 criteria)

84.9

\begin{tabular}{ll}
\hline$\%$ meeting 1+ criteria & 100.0 \\
\hline$\%$ meeting 2+ criteria & 100.0 \\
\hline$\%$ meeting 3+ criteria & 99.7 \\
\hline$\%$ meeting 4+ criteria & 99.1 \\
\hline$\%$ meeting $5+$ criteria & 95.3 \\
\hline$\%$ meeting 6+ criteria & 84.9 \\
\hline$\%$ meeting 7+ criteria & 64.7 \\
\hline$\%$ meeting $8+$ criteria & 37.0 \\
\hline$\%$ meeting 10 criteria & 13.1 \\
\hline
\end{tabular}

Source CLP-2 IMLC division, unpublished graduation report, October 2014. once CLP's assistance ends - what Samson (this IDS Bulletin) calls an 'exogenous exit'.

CLP recognises that 'graduation' and 'sustainably moving out of extreme poverty' are not the same thing. For CLP, graduation monitors the short- and medium-term impact of the programme, recognising that some aspects of poverty, for example institutional changes in power structures, may not change detectably over programme timescales. Indicators that are relevant for shortto medium-term outputs/outcomes may not be as relevant when considering a longer time frame.

CLP treats graduation as a 'one-way door' for programmatic and reporting purposes, even while recognising that some households will not graduate; and some will slip back under the extreme poverty line. An annual survey of a panel sample of CLP-1 and CLP-2 participants takes place to track the sustainability of graduation.

CLP-2 does not have the capability of assisting households once each cohort reaches the end of the CLP cycle. Reductions in rates of graduation over time are therefore not something that CLP-2 can respond to directly, i.e. through additional support to any previous cohort. It aims to learn lessons, however, and modify procedures and activities for future cohorts in order to support sustainability.

\section{CLP-2 graduation monitoring system}

The Innovation, Monitoring, Learning and Communications (IMLC) division is responsible for assessing progress against graduation targets.

Baseline data are collected from a sample of households as they join the programme, on a number of thematic areas including: women's empowerment, water, sanitation and hygiene (WASH), nutrition, food security, livelihoods as well as graduation. At the same time, the IMLC division collects follow-up data from a panel 
Household consumed 3 meals in a day and 5-plus food groups in a week

96.2

\begin{tabular}{ll}
\hline Participant is part of a committee or social group & 93.6 \\
\hline Presence of ash/soap near to water point or latrine & 91.0 \\
\hline Homestead is on a flood-protected plinth & 81.4 \\
\hline Participant is able to influence household decisions & 79.6 \\
\hline Household has access to a CLP-standard sanitary latrine & 74.0 \\
\hline Household had more than one income source & 60.0 \\
\hline
\end{tabular}

Source IMLC data sets, CLP, unpublished.

sample of households from each of the previous cohorts, including CLP-1 households. Sample sizes are 410 CPHHs for each of the CLP-2 cohorts and 650 CPHHs for CLP-1. Data collection and data entry are outsourced.

During the 18-20 month period of support, the IMLC division also collects data from a sample of CPHHs (410), every two months. Once again, data collection and data entry are outsourced. These bi-monthly surveys collect information on a reduced range of indicators but include income, expenditure, asset status and graduation-related indicators.

To assess graduation rates a household must meet (any) six or more of the graduation criteria within three months of CLP support ending. The final bi-monthly survey is used to assess graduation. CLP only finalised its graduation criteria early in 2014. This created a challenge, in particular for Cohorts 2.1 and 2.2 in terms of assessing exact graduation rates because not all questions related to graduation were asked during the final bimonthly surveys for each of these cohorts.
To assess the extent to which graduation rates are sustainable the CLP uses the annual followup surveys.

\section{CLP.2 graduation in practice}

Table 3 shows CLP-2's graduation rates.

The lower graduation rate for Cohort 2.1 is likely due to methodology issues. The graduation criteria were only recently concluded (March 2014). Data came from two separate surveys, depending on indicator; one survey before the end of support and one survey ten months after support ended. Data from the second survey were therefore effectively looking at sustainability of graduation from some indicators, rather than necessarily the households' position within three months of completing CLP-2 assistance. The figures in Table 3 are therefore likely to be underestimating graduation rates for Cohort 2.1.

Table 4 gives a sensitivity analysis, indicating the percentages of the CLP-2 cohorts that meet between zero and ten indicators.

Table 6 CLP-2 graduation indicators that are not being met by large proportions of participants

\section{Indicator}

Mean \% of households meeting the indicator within 3 months of support ending, Cohorts 2.1-2.4

40.4 
Analysis of data from the most recent round of surveys (June 2014) indicates that the seven indicators in Table 5 are being met by large proportions (i.e. above 60 per cent) of the CLP-2 participant population.

Table 6 shows the graduation indicators that a lower percentage of CLP-2 participants are meeting.

Using the data above, this article next assesses the likely factors that constrain, enable and sustain graduation from the programme. These will be identified at the policy, environment or household level, as appropriate.

\section{Factors that constrain graduation 6.1 Policy/design constraints}

A major overarching factor that acted as a constraint to graduation in CLP's case was at the design or policy level. CLP was not initially designed to be a 'graduation-focused' programme. The concept of graduation was only added to the programme's logframe during implementation. This had a number of impacts.

The first major impact was to do with the focus of the programme's activities. The indicator 'access to improved water' provides a clear example. Before the graduation indicators were finalised, CLP saw improved water as a 'wholecommunity' benefit. There was no specific focus on CLP's participants; improved water supplies (IWSs) were installed where five or more households could access them. However, the graduation criteria were specifically focused on CPHHs. As a result, CLP did not specifically give CPHHs an IWS, but graduation required it.

During January 2013, an internal CLP-2 unpublished report looked at the impact on graduation rates of varying the criteria for improved water. This indicated that many CPHHs had access to some kind of IWS, but that it often did not meet CLP's standards, particularly the need to have a concrete apron to prevent contamination of the water table via the wellhead. Excluding the need for this apron showed overall graduation rates rise by 19 per cent.

As a result, CLP-2 instigated a policy shift for its IWS project, which entailed targeting current CLP-2 participants for a CLP-standard IWS as well as going back to completed cohorts.
This illustrates that graduation-focused programmes need to have their graduation criteria designed-in from the start, and the programme's approach and outputs need to be aligned with the graduation indicators.

A second impact is that, because CLP's graduation criteria were not ready to apply until late 2012, data on some of the criteria were not collected at the completion of Cohorts 2.1, 2.2 and 2.3 (which finished in December 2011, June 2012 and June 2013 respectively). This has meant that a suite of similar graduation data will be available only for Cohorts 2.4, 2.5 and 2.6. CLP-2 will estimate similar graduation figures for the earlier cohorts.

This also means that these cohorts did not benefit from programmatic improvements and modifications that could have boosted their graduation rates. More recent cohorts are therefore more likely to show better graduation figures as a result.

Another design consideration that impacts on rates of graduation is the choice of indicator/s and the thresholds that are set for achieving the indicators. An example of this is the CLP's indicator for food security, which was initially defined as 'achieving an "acceptable" Food Consumption Score (FCS)'.

The FCS method was developed by the World Food Programme (WFP 2008). It is a weighted score based on dietary diversity, food frequency and the nutritional importance of food groups consumed. The maximum FCS has a value of 112, which would be achieved if a household ate each food group every day during the last seven days. The total scores are then compared to preestablished thresholds. For Bangladesh (and therefore the chars), considering the importance of fish and oil in the Bangladesh diet, an FCS of 42 or over would be considered 'acceptable' by the World Food Programme (WFP 2009).

While this measure is supported by WFP, it has some drawbacks. Of particular relevance to CLP is that it consolidates aspects of both programme outputs (providing a livelihood and increased income that leads directly to increases in food availability and access) with aspects of outcomes (behaviour change towards eating 'healthier' or more nutrition-dense foods). 
Many governments and societies are currently struggling to encourage healthy eating habits among their citizens, even developed countries with good levels of resources (financial, human and institutional) that have promoted such changes for decades.

Comparing controls to previous cohorts, two things became clear:

1 the FCS jumps significantly, from 5.6 per cent of control HHs achieving an 'acceptable' score to an average of 36 per cent of CLP participants (Barrett, Hannan and Alam 2014); however, no cohort substantially exceeded this level; and

2 households reporting the ability to eat three meals a day and consume more than five food groups in the previous week jumped from 26.3 per cent of the control HHs to 98.2 per cent for Gohort 2.4.

Although CLP-2 does not have data or analysis to definitively explain this positive impact, it is likely that it is due to both increasing incomes and increasing awareness, i.e. through the livelihoods component as well as the capacity-building and awareness-raising nutrition component.

CLP decided that the FCS was not realistic as a graduation indicator because of the nature of the behavioural change required and the timescale in which the programme had to achieve it; it was too high a standard to expect the programme to achieve in the time. Therefore the 'three meals a day + five food groups' indicator replaced the FCS. CLP-2 continues to track the FCS as it provides information on longer-term outcomes.

\subsection{Household-level constraints}

\subsubsection{Asset values}

CLP conducted research during 2012 and early 2013 (Barrett et al. 2014) into various aspects of asset values. Two groups of ex-CLP participants were studied - those whose asset values had increased to BDT70,000 or above (about $£ 583$ ) and those whose asset values had fallen to BDT7,500 or below (about £63).

The survey showed that around 23 per cent of households possessed productive assets worth BDT10,000 or less, while just over 18 per cent were 'super-graduates', having assets worth BDT70,000 or above.
When asking respondents in the second, lowasset category what had caused their asset values to drop so significantly, four reasons stood out:

1 Poor reinvestment. Profits from assets were used in a manner that left the household without further productive capacity, for example, to re-build houses or purchase food. While this may have been necessary (for example, river erosion or another external shock), nevertheless it caused the household to lose its productive capacity.

2 Payment of dowry. Although illegal since the 1980 s, paying dowry is still a very strong cultural and social expectation on the chars. Although households with higher asset values also reported paying dowries, the impact was greater for those households with low asset values.

\section{Investment in land that was then eroded.}

Some households invested in land leases for agriculture. However, they did not maintain a diversified livelihood, so when floods eroded this land or covered it in non-fertile sand, the household's livelihood was destroyed. Highasset-value households reported strongly that diversified livelihoods was a key reason for their continuing success.

4 Payment of loans. These loans may have been taken out for dowries or for other purposes. However, due to high interest rates and, possibly, poor reinvestment decisions, households reported that they had to liquidate their productive assets to repay the loans.

The reasons given above indicate that shocks such as erosion or human-centred decisions, such as paying dowries or investing unwisely, can rob households of their productive assets. Recent data show that almost 49 per cent of CLP-2 households achieve this criterion (having more than or equal to BDT30,000 in productive assets), while just 0.2 per cent of the control group (Cohort 2.5) reach this threshold.

\section{Factors that enable graduation 7.1 Policy/design considerations}

Similar design considerations work for 'enablers' as they do for 'constrainers', i.e. the appropriate programme activities need to be designed-in to the programme from the start. In the case of 
CLP, it provides a wide-ranging and integrated package of support to participants. Programme designers should be wary of setting graduation criteria too far towards outcomes and impacts, and also of expecting large spillover effects. If a project or programme does not include activities that directly influence an indicator, it is questionable whether it is appropriate as a graduation indicator. In the case of the CLP-2, most of the indicators are directly affected or influenced by CLP-2, thus making them appropriate for measuring the effects of the programme.

\subsection{Environment - reducing vulnerability}

The physical environment of the chars has a major effect on graduation. By definition, chars are riverine islands. This means that households are constantly vulnerable to inundation and erosion. To assist in reducing this vulnerability, CLP constructs plinths to raise participants' homesteads above the flood waters.

While this is an important graduation indicator in its own right - and an average of 81.4 per cent of surveyed ex-participants (CLP2.1 to CLP2.4) still reside on their raised plinth - it also has a major impact on other indicators. If a CLP participant loses their plinth:

- productive assets may be lost, impacting on the 'asset value' indicator;

- with productive assets lost, families may no longer have multiple sources of income;

- lower income often means not being able to eat three times a day and reducing the diversity and quality of food;

- having an independent income for the female is highly correlated with influence in household decisions (where she is not household head), so losing this source of income may decrease the woman's say in the household;

- cash savings are likely to be depleted in re-locating and re-housing the family; and

- if the family moves away from the area in which they participated in a group, such as the Village Development Committee (VDC) or Village Savings and Loans Group (VSLG), then this indicator may also suffer.

Another study (Haneef et al. 2014c) into the impact of an independent income on women's empowerment also found that the independent income was highly correlated with many of the other empowerment indicators. It could therefore be argued that this one indicator could be used as a proxy for many of the others, simplifying data collection and analysis.

\subsection{Household-level factors}

The criterion 'participant is able to influence household decisions (regarding investments)' is also indicative of interrelated factors that enable graduation. This criterion was chosen with an eye on the main asset that CLP-2 transfers usually cattle. If the female participant is not able to influence the use of this asset or profits derived from it, then it is possible the benefits may be captured by males or not used for household purposes. It is one of ten criteria that CLP developed in a participatory fashion with the women of the chars; part of CLP's 'Women's Empowerment Scorecard' (McIntosh 2012).

Data from the 2013/14 Annual Socioeconomic Survey (Haneef et al. 2014a) shows that, for all CLP-2 cohorts (2.1 to 2.4), the average percentage of respondents that could influence investment decisions was 84.4 per cent. Given that just 12.5 per cent of control participants reported the same, this shows the tremendous empowerment impact of the CLP.

What drives this substantial improvement in ability to influence decisions? Research indicates that the transfer of the CLP asset results in a significant boost to the woman's standing within the household. This comes from the simple fact of owning a valuable and high-status asset, but also from the training they receive; their knowledge increases in areas that are held in high esteem by men.

One female GLP participant said, 'Before [CLP], [my husband] didn't discuss anything with me, which we often used to quarrel about. But now it doesn't happen anymore. Since I can contribute to the family income, my husband values me and my opinion.' One male participant was overheard saying, 'My wife has become clever.' With valued knowledge and an independent income comes the empowerment of women.

\section{The sustainability of graduation and factors that support it}

CLP-2 collects data annually from a panel survey of CLP- 1 and CLP-2 cohorts. The CLP-1 cohort is Cohort 1.4, i.e. the cohort that completed CLP 
Table 7 Sustainability of graduation rates: the difference between CLP-1 and CLP-2 Cohort 2.4

\begin{tabular}{|c|c|c|c|}
\hline Indicators & CLP-1 & Indicators & CLP2.4 \\
\hline $\begin{array}{l}\text { Presence of ash/soap near to water point } \\
\text { or latrine }\end{array}$ & 100.0 & Participant is able to influence $\mathrm{HH}$ decisions & 100.0 \\
\hline Participant is able to influence $\mathrm{HH}$ decisions & 83.8 & Part of a committee or social group & 100.0 \\
\hline Homestead is on a flood-protected plinth & 76.0 & Three meals a day + five food groups & 98.2 \\
\hline Three meals a day + five food groups & 82.1 & Access to sanitary latrine (all criteria) & 88.0 \\
\hline Productive assets worth $>=$ BDT30,000 & 55.9 & Homestead is on a flood-protected plinth & 87.5 \\
\hline Access to sanitary latrine (all criteria) & 52.5 & $\begin{array}{l}\text { Presence of ash/soap near to water point } \\
\text { or latrine }\end{array}$ & 71.4 \\
\hline $\mathrm{HH}$ has had more than one income source & 42.1 & Has access to improved water & 66.4 \\
\hline Part of a committee or social group & 34.4 & Productive assets worth $>=$ BDT30,000 & 53.6 \\
\hline $\mathrm{HH}$ has cash savings of more than BDT3,000 & 25.5 & $\mathrm{HH}$ has had more than one income source & 51.8 \\
\hline Has access to improved water & 21.3 & $\mathrm{HH}$ has cash savings of more than BDT3,000 & 9.1 \\
\hline
\end{tabular}

Source IMLC data sets, CLP, unpublished.

assistance in 2010. This cohort therefore allows a comparison between more recent cohorts and earlier cohorts, allowing CLP-2 to trace which indicators change, and in what directions, over time.

Using CLP-1 data as a proxy for 'sustainability', Table 7 shows the differences between the individual indicator percentages between CLP-1 and CLP-2 Cohort 2.4. In the CLP-1 columns, the indicators are arranged into three coded clusters: 'good' in bold type (those indicators that score 60 per cent or above); 'medium' in medium type (indicators between 40 per cent and 59.9 per cent); and 'weak' in light type (those indicators that score less than 40 per cent).

The CLP2.4 indicator descriptions remain in the same grey-coded background as they were under CLP-1, while the percentages are grey-coded according to their group, i.e. 'good', 'medium', or 'weak'.

The table clearly indicates that more recent cohorts are more likely to achieve higher percentage achievements across more indicators. This is not surprising, given that recent cohorts have only just completed their CLP assistance. The top four indicators for CLP-1 participants are also in the top six for CLP2.4, showing that these indicators have the potential to sustain well over time.
The 'committee or social group' indicator shows a particularly marked difference, going from the 'weak' category for CLP-1 to a 'good' category for CLP-2 Cohort 2.4, with 100 per cent achievement. This is almost certainly due to the fact that several of the social development groups directly supported by CLP-2 continue operations for some time after the end of CLP-2. CLP research indicates that around 32 per cent of VSLGs from CLP-1 were continuing operations as of 2012 (McIvor and Hussain 2012), while research into Village Development Committees (Haneef et al. 2014b) showed that up to 20.2 per cent of VDCs continued operating for some time. It is therefore not surprising that this indicator may show a decline over time as social groups either disband or people decide that they no longer want or need to be involved.

For the ash/soap criteria, it seems fairly obvious that the factors that enabled this high graduation rate - the relative ease of meeting it, combined with the multiple mechanisms and interrelated support - clearly sustain it. It is gratifying to see that the empowerment criterion of women's ability to influence household decisions also sustains strongly across cohorts. It is also likely that the twin factors that enabled graduation in terms of this criterion - economic improvements and increased knowledge - continue to sustain it. The reduction in vulnerability through plinthraising also probably continues to sustain 
graduation rates, given its importance in enabling many of these indicators.

It is interesting that the criterion for asset values remains fairly stable across the two cohorts. Although it does not reach 'good' status, nevertheless it consistently sustains in the medium bracket. Two factors that help households to sustain their graduation in terms of the 'asset values' indicator are good management of cattle and diversification of livelihoods (Barrett et al. 2013). In that study, households that succeeded in raising their asset values to above BDT70,000 were asked what the main reason for their success was; 40 per cent reported that it was the combination of managing cattle well and also investing in land. This suggests that the cattle management training received by participants is critical to ensuring that they can raise their asset values significantly and both achieve and sustain graduation. It also suggests that CLP needs to focus attention on supporting diversification of livelihoods. Barrett et al. (2013) makes it clear that diversified livelihoods are much more resilient in dealing with external and internal shocks, such as erosion, dowry payments or illness, and thus sustaining graduation.

Although CLP does not have data to support the hypothesis, it is worth asking whether better graduation rates would be achieved for this indicator if the timescale of CLP assistance was longer.

\section{Conclusion}

It has taken CLP some time to conclude its graduation criteria and approaches. This has been driven partly by the inherent tensions of setting threshold-based 'pass' marks. Defining graduation is also not easy. Different stakeholders have different interpretations of what graduation means and how to measure it, as evidenced by the differing approaches of each of CLP's annual review teams that were tasked to assess it.

Key lessons that CLP has learned are as follows:

1 A graduation focus has broad implications for the programme, from the targeting of assistance, to the type of assistance needed, to the operational implications of delivering the assistance. If a programme is to take a graduation approach, it should do so from the outset.

2 It therefore follows that the purpose of using a graduation approach, the definition of graduation, and the approach and monitoring system all need to be discussed and agreed in advance. Does graduation mean movement from extreme poverty? Or is it more about leaving the programme? Answers to these questions should be informed by a sound theory of change that should also be articulated as early as possible.

3 Graduation should be kept as simple as possible within the objectives set for it, and it should include the community's input where possible. If the community does not recognise or agree with major indicators or thresholds, their sustainability is questionable and arguably they become less relevant as a measure of programme success.

4 There should be a strong and appropriate logic for the selection of thresholds, which should be evidence-based where possible. There is little point saddling the programme with unattainable graduation targets; but few will be convinced by, and little will be learned from, thresholds that are too low.

5 The sustainability of graduation should not be overlooked. It is also worth thinking about whether indicators of graduation remain valid and important as time from graduation lengthens. Other indicators may become more relevant as participants continue their journey out of extreme poverty; but these indicators may be less related to the programme's outputs and outcomes, and thus less attributable.

6 Graduation indicators may have interrelations that may have a large or even distorting effects on graduation rates. In CLP's case, the reduction in vulnerability through plinths is possibly implicated in supporting many other graduation indicators. In addition, CLP-2 research also indicated that an independent income could potentially serve as a proxy for several of the other indicators of women's empowerment. 


\section{References}

Barrett, A.T.; Hannan, M. and Alam, Z. (2014) The Impact and Sustainability of CLP's Food Security Interventions, Dhaka, Bangladesh: CLP Barrett, A.T.; McIntosh, R.A.; Pritchard, M.; Hannan, M.; Alam, Z. and Marks, M. (2013) Asset Values: Why are Some Households Doing Better than Others?, Dhaka, Bangladesh: CLP-2/DFID

CLP (Chars Livelihoods Programme) (2014) 'Logical Framework', unpublished internal document, CLP-2/DFID, www.clp-bangladesh.org (accessed 16 December 2014)

Gadhavi, V. and Pettersson, M.S. (2013) Proposal to Measuring Graduation from Extreme Poverty at EEP/Shiree, Dhaka, Bangladesh: Shiree/DFID

Government of Bangladesh (2010) Household Income and Expenditure Survey: Key Findings and Results, www-wds.worldbank.org/external/ default/WDSContentServer/WDSP/IB/2012/ 07/12/000386194_20120712025531/Rendered/ PDF/709500WP00PUBL0AndExpenditure Survey.pdf (accessed 29 October 2014)

Haneef, C.; Kenward, S.; Hannan, M.; Pritchard, M. and Alam, Z. (2014a) CLP's Impact on Women's Empowerment on the Chars and its Sustainability, http://clp-bangladesh.org/wpcontent/uploads/2014/11/2014-11-20-CLP_ WomensEmpowerment_impact-andsustainability.pdf (accessed 14 January 2015)

Haneef, C.; Pritchard, M.; Hannan, M.; Alam, Z. and Rahman, M. (2014b) A Study into the Effectiveness and Sustainability of Village Development Committees, Dhaka, Bangladesh: CLP-2/DFID

Haneef, C.; Pritchard, M.; Hannan, M.; Kenward, S.; Rahman, M. and Alam, Z. (2014c) Women as Entrepreneurs: The Impact of Having an Independent Income on Women's Empowerment, Dhaka, Bangladesh: CLP-2/DFID

Hashemi, S. and Umaira, W. (2011) New Pathways for the Poorest: the Graduation Model from BRAC, CSP Research Report 10, Brighton: IDS

Hodson, R. (2010) The Chars Livelihoods Programme: The Story and Strategy So Far, Dhaka, Bangladesh: CLP-2/DFID
Kenward, S. and Hannan, M. (2014) Chars Livelihoods Programme: Graduation: Results for Cohorts 2.1 to 2.4, http://clp-bangladesh.org/ wp-content/uploads/2014/11/2014-11-10Graduation-2-1-to-2-4-Brief.pdf (accessed 14 January 2015)

Kenward, S. and Islam, R. (2010) CLP-2 Districts: An Assessment of the Number of Core Participant Households and Island Char Villages, http://r4d.dfid.gov.uk/PDF/Outputs/CLP/ baseline_status_new_districts.pdf (accessed 14 January 2015)

Kenward, S.; Blackie, R. and Islam, R. (2012) The CLP's Approach to Defining Graduation, Dhaka, Bangladesh: CLP-2/DFID

Kenward, S.; Blackie, R. and Islam, R. (2011) Review of the CLP's Selection and Graduation, Dhaka, Bangladesh: CLP-2/DFID

Maxwell Stamp Plc (2010) Final Report, Bangladesh's Chars Livelihoods Programme (CLP), London: Maxwell Stamp Plc

McIntosh, R.A. (2012) Reviewing the CLP's Approach to Measuring Women's Empowerment, Dhaka, Bangladesh: CLP-2/DFID

McIvor, N. and Hussain, A. (2012) Study to Assess the Sustainability and Quality of Village Savings and Loans Groups (VSLGs), Dhaka, Bangladesh: CLP-2/DFID

WFP (2009) Food Consumption Score (FCS) in Bangladesh Context, Technical Guideline, World Food Programme, http://foodsecuritycluster.net/ sites/default/files/WFP_BAN_FGS\%20 technical\%20guideline_Bangladesh\%20context Jan09.pdf (accessed 16 December 2014)

WFP (2008) Calculation and Use of the Food Consumption Score in Food Security Analysis, Rome: VAM Unit, World Food Programme, http://documents.wfp.org/stellent/groups/ public/documents/manual_guide_proced/ wfp197216.pdf (accessed 16 December 2014) 